\title{
Research Paper: Electrocardiogram Changes in Patients With Acute Ethanol Poisoning
}

\author{
Gholamali Dorooshi $^{1}$ Q, Mahsa Akafzadeh Savari², Farzaneh Nayeri ${ }^{2}$, Rokhsareh Meamar $^{1 *}$, Mohammad Javad Tarrahi ${ }^{3}$, Nastaran Eizadi-Mood $^{1}$
}

1. Department of Clinical Toxicology, Isfahan Clinical Toxicology Research Center, School of Medicine, Isfahan University of Medical Sciences, Isfahan, Iran

2. Isfahan Clinical Toxicology Research Center, Isfahan University of Medical Sciences, Isfahan, Iran.

3. Department of Epidemiology \& Biostatistics, School of Health, Isfahan University of Medical Sciences, Isfahan, Iran

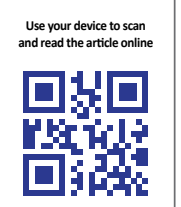

Citation: Dorooshi Gh, Akafzadeh Savari M, Nayeri F, Meamar R, Tarrahi MJ, Eizadi-Mood N. Electrocardiogram Changes in Patients With Acute Ethanol Poisoning. International Journal of Medical Toxicology and Forensic Medicine. 2021; 11(2):33353. https://doi.org/10.32598/ijmtfm.v11i2.33353

https://doi.org/10.32598/ijmtfm.v11i2.33353

Article info:

Received: 18 Dec 2020

First Revision: 29 Dec 2020

Accepted: 23 May 2021

Published: 15 Jun 2021

\section{A B STRACT}

Background: Alcohol consumption leads to a significant number of deaths, mostly in men, worldwide. Considering the effect of ethanol toxicity on the heart, we studied various Electrocardiographic (ECG) changes in patients with acute ethanol poisoning.

Methods: A cross-sectional study was performed on patients admitted to Khorshid Hospital (affiliated to Isfahan University of Medical Sciences) due to ethanol poisoning. All 15- to 50 -year-old patients with acute ethanol intoxication were included in the study $(\mathrm{N}=250)$. The patients' information, including the demographic characteristics, clinical manifestations, and ECG changes were recorded and analyzed. Different variables were compared between the patients with or without ECG changes.

Results: Most of the research patients $(\mathrm{n}=208)$ were men $(83.82 \%)$. The Mean \pm SD age of the study patients was $26.8 \pm 8.87$ years. About $54.8 \%$ of the patients presented abnormal ECG. The changes in ECG were not significantly different based on the demographic characteristic and clinical manifestations. The time interval between ethanol consumption and admission was significantly higher in patients with abnormal ECG, compared to those with normal ECG (Mean \pm SD: $7.09 \pm 10.67$ vs. $4.77 \pm 4.54$ hours, respectively) $(\mathrm{P}=0.03)$.

Conclusion: ECG changes are common in patients with ethanol poisoning. The time interval between ethanol consumption to hospital admission may be an important factor in the occurrence of ECG changes.

\section{Introduction}

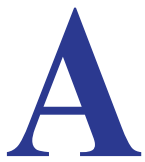

lcohol use presents multifaceted effects on Cardiovascular (CV) health [1]. According to the World Health Organiza- tion (WHO), alcohol consumption leads to three million deaths annually; such cases involve men three times more than women globally. Alcohol is considered a significant risk factor of mortality in 15-59-year-old males [2]. Alcohol dependency is not prevalent in Iran; in most

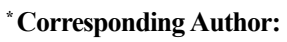

Rokhsareh Meamar, MD.

Address: Department of Clinical Toxicology, Isfahan Clinical Toxicology Research Center, School of Medicine, Isfahan University of Medical Sciences,

Isfahan, Iran.

Tel: +98 (913) 3091206

E-mail:meamar@pharm.mui.ac.ir 
cases, alcohol consumption and its adverse effects may not be reported due to social stigmas [3].

The acute effects of alcohol consumption are related to drinking habits as well as functional and metabolic tolerance. It is necessary to recognize the pattern of alcohol consumption to find the exact relationship between clinical symptoms and ethanol serum level. Some of the drunken patients present such signs and symptoms, as flushing, sweating, tachycardia, and hypotension [4]. Drunkenness in patients with underlying diseases causes decreased cardiac output and arrhythmias, such as atrial fibrillation, atrioventricular blocks, and unstable ventricular tachycardia. Such conditions can lead to ventricular fibrillation, even in the healthy population $[4,5]$. Cardiac arrhythmias may occur during or shortly after consumption in patients who regularly drink alcohol. It may also occur in non-alcoholic patients during consumption [6]. Atrial fibrillation has been observed in $15^{\wedge}-20 \%$ of individuals with acute alcohol toxicity. Other arrhythmias, unspecific changes, including ST section changes, P wave changes, left ventricular complete or partial block, and other conductive disorders have been reported in various studies [7, 8]. Ethanol can cause ST-segment elevation in Electrocardiogram (ECG) and angina due to local spasm in the coronary artery [4]. Considering the different metabolism of ethylic alcohol in various races, we have investigated the frequency of ECG changes in Iranian patients with ethanol toxicity.

\section{Materials and Methods}

This cross-sectional study was conducted on 250 patients intoxicated with ethyl alcohol, who were hospitalized in Khorshid Hospital, affiliated to Isfahan University of Medical Sciences, from 23 July 2018 to 20 March 2019. This study was approved by the Ethics Committee of Isfahan University of Medical Sciences (code: IR.MUI.MED.REC.1397.173). All the included patients or their guardians provided a written consent form to participate in this research.

Patients in the age range of 15-50 years who were referred to the Toxicology Emergency Department of Khorshid Hospital due to acute ethylic alcohol toxicity (a recent consumption of drinks, including wine, whiskey, vodka, beer, and other available alcoholic drinks, e.g. illegally-produced alcohol beverage) were included in this study. Considering that methanol was the main toxic chemical component in illegal alcoholic beverages [9], the consumption of this product was considered as the inclusion criteria, except for the patients with any sign and symptoms unrelated to ethanol toxicity. Having a medical history of cardiovascular diseases, diabetes mellitus, and hypertension were considered as the exclusion criteria of the study. The demographic data of the study patients were recorded, including age, gender, vital signs and consciousness level, the duration of alcohol consumption, the amount and type of consumed alcohol, the coingestion of effective drugs on the cardiovascular system, acute or chronic opioids, and stimulant drugs consumption, underlying diseases, and the period between alcohol consumption and hospital admission. Laboratory tests, including electrolytes (Na, K), Blood Sugar (BS), Aspartate Aminotransferase (AST), Alanine Aminotransferase (ALT), Lactate Dehydrogenase (LDH), Creatine Phosphokinase (CPK), Complete Blood Count (CBC), coagulation tests (INR, PT, PTT), and Venous Blood Gas (VBG) were gathered. Furthermore, a standard ECG with 12 leads was obtained by Yasham 636 in the supine position from all research patients; subsequently, its changes were recorded according to standard evaluation. ECGs were evaluated based on the heart rate, PR segment, QRS complex, and QT interval. The $\mathrm{PR}$ range of 0.12-0.20 second, the QRS complex range of 0.06-0.1 second, and the corrected QT interval (QTc) of $<0.45$ second for males and $<0.46$ second for females were considered as normal [4]. Abnormal PR was considered as tachycardia of $>100 / \mathrm{min}$ and bradycardia of $<60 / \mathrm{min}$. Additionally, arrhythmias (including atrial fibrillation, premature ventricular contractions, ventricular, \& supraventricular tachycardia) and any changes out of the aforementioned ranges were defined as abnormal ECG. Different variables were compared between the patients with normal and abnormal ECGs.

The obtained data were analyzed by SPSS V 23. The collected descriptive data were reported using mean $\pm \mathrm{SD}$, percentage, and absolute count. Moreover, the achieved data were analyzed using Chi-squared or Fisher's Exact tests, Independent Samples t-tes, and Analysis of Variance (ANOVA). $\mathrm{P}<0.05$ was considered statistically significant.

\section{Results}

According to the present study results, of the 250 patients, $208(83.2 \%)$ cases were men and 42 (16.8\%) cases were women. The Mean \pm SD age of the study participants was $26.4 \pm 8.87$ years. In $54.8 \%$ of the patients, the ECG was abnormal and $45.2 \%$ of patients presented normal ECG. In $55.29 \%$ of men and $52.38 \%$ of women, the ECG was abnormal. The most common findings in ECG were arrhythmias and heart rate abnormalities (Table 1).

The PR range of 0.12-0.20 second, QRS complex range of $0.06-0.1$ second, and corrected QT interval 
Table 1. The frequency of ECG findings in patients with alcohol poisoning

\begin{tabular}{|c|c|c|}
\hline Variable & \multicolumn{2}{|c|}{ No. (\%) } \\
\hline & Wide & $1(0.4)$ \\
\hline \multicolumn{3}{|l|}{ QRS Complex (second) } \\
\hline & Normal & 249 (99.6) \\
\hline \multirow{3}{*}{ Corrected QT Interval (females) (second) } & Normal & 41 (97.6) \\
\hline & & \\
\hline & Abnormal & $1(2.4)$ \\
\hline \multirow{4}{*}{ Corrected QT Interval (males) (second) } & Normal & $176(84.6)$ \\
\hline & & \\
\hline & Abnormal & $32(15.4)$ \\
\hline & Sinus bradycardia & $3(1.2)$ \\
\hline \multirow[t]{2}{*}{ Heart Rate/min } & Sinus tachycardia & $39(15.6)$ \\
\hline & Normal & $208(83.2)$ \\
\hline \multirow{3}{*}{ Cardiac Arrhythmia } & Yes & $137(54.8)$ \\
\hline & & \\
\hline & No & $113(45.2)$ \\
\hline
\end{tabular}

(QTc) of $<0.45$ second for men and $<0.46$ second for women were considered as normal. The pulse rate of $<60 /$ min was set as bradycardia and $>100$ per min as tachycardia. Cardiac arrhythmias included atrial fibrillation, premature ventricular contractions, ventricular, and supraventricular tachycardia.

Comparing the demographic and clinical findings of the studied patients with normal and abnormal ECG are represented in Table 2. The time between ethanol consumption and admission to the emergency department in patients with abnormal ECG was significantly higher than in the group with normal ECG $(\mathrm{P}=0.03)$. A comparison of the collected laboratory data between the study groups with normal and abnormal ECG is represented in Table 3.

\section{Discussion}

The ECG findings in the patients who were hospitalized for acute ethanol toxicity were investigated in this study; we compared the demographic and clinical features as well as the laboratory data between the study groups. Approximately $54.8 \%$ of the patients with methanol toxicity presented abnormal ECG; however, we found no significant difference between the patients with normal and abnormal ECG concerning the demographic and clinical features or laboratory parameters. However, only the time interval between ethanol consumption and admission was significantly higher in patients with abnormal ECG, compared to those with normal ECG.
Similar to all other studies, alcohol toxicity was more prevalent in men in our study [10-12]. The present study suggested that the patients with alcohol toxicity were averagely in the third decade of their lives. Eskandarieh et al. also revealed that individuals who heavily drink alcohol are mostly males in the age group of 18-30 years [13]. According to international studies, the most common age group of individuals with alcohol toxicity is 40-60 years $[14,15]$. Alcohol toxicity at this age range is usually due to the acute consumption of a large amount of alcohol, following the first experience of alcohol ingestion in our society; however, in other societies, it may be caused by chronic alcohol consumption in alcohol-dependent individuals $[1,13]$. The demographic findings of our study are consistent with those of Verelst [16].

Furthermore, the time interval between alcohol consumption and emergency department admission was the only variable,i.e. significantly higher in patients with abnormal ECG findings. Patients with abnormal ECG were admitted to the hospital significantly later. Such a condition may cause complete ethyl alcohol absorption leading to a gradual rise in the acetaldehyde level. Acetaldehyde accumulation causes dysfunction in heart contraction and function with the prevention of protein synthesis in myocardium muscles [3].

A limitation of this study was the unavailability of blood ethanol and acetaldehyde level tests for bet- 
Table 2. Comparing demographic findings and clinical examination data in alcoholic patients with normal and abnormal electrocardiogram

\begin{tabular}{|c|c|c|c|c|}
\hline \multirow{2}{*}{\multicolumn{2}{|c|}{ Variable }} & \multicolumn{2}{|c|}{$\begin{array}{l}\text { Mean } \pm S D / \text { No. (\%) } \\
\text { Electrocardiogram }\end{array}$} & \multirow{2}{*}{$\mathbf{P}$} \\
\hline & & Normal ( $\mathrm{N}=113$ ) & Abnormal ( $\mathrm{N}=137$ ) & \\
\hline \multicolumn{2}{|l|}{ Age (y) } & $26.59 \pm 9.75$ & $26.24 \pm 8.11$ & 0.75 \\
\hline \multicolumn{2}{|c|}{ Weight (Kg) } & $78.30 \pm 49.62$ & $72.31 \pm 12.21$ & 0.17 \\
\hline \multirow{2}{*}{ Gender } & Male & $93(82.3)$ & $115(83.9)$ & \multirow{2}{*}{0.73} \\
\hline & Female & $20(17.7)$ & $22(16.1)$ & \\
\hline \multirow{3}{*}{ Medical history } & Yes & $6(5.3)$ & $7(5.1)$ & \multirow{3}{*}{$0.9<$} \\
\hline & & & & \\
\hline & No & $107(94.7)$ & 130 (94.9) & \\
\hline \multirow{7}{*}{$\begin{array}{l}\text { The duration of alcohol } \\
\text { consumption }\end{array}$} & First Time & $49(43.4)$ & $54(39.4)$ & \multirow{7}{*}{0.73} \\
\hline & 1 month & $2(1.8)$ & $2(1.5)$ & \\
\hline & 3 months & $5(4.4)$ & $9(6.6)$ & \\
\hline & 6 months & $7(6.2)$ & $10(7.3)$ & \\
\hline & 1 year & $18(15.9)$ & 19 (13.9) & \\
\hline & 5 years & $23(20.4)$ & $37(27)$ & \\
\hline & $>5$ years & $9(8)$ & $6(4.4)$ & \\
\hline \multirow{2}{*}{ Drug use history } & Yes & $12(10.6)$ & $24(17.5)$ & \multirow{2}{*}{0.12} \\
\hline & No & $101(89.4)$ & $113(82.5)$ & \\
\hline \multirow{2}{*}{ Drug abuse } & Yes & $20(17.7)$ & $23(16.8)$ & \multirow{2}{*}{0.84} \\
\hline & No & $93(82.3)$ & $114(83.2)$ & \\
\hline \multirow{4}{*}{$\begin{array}{l}\text { Kind of co-ingested opioids or } \\
\text { stimulants }\end{array}$} & No co-ingestion & $91(80.5)$ & $113(82.5)$ & \multirow{4}{*}{0.25} \\
\hline & Opium & $11(9.7)$ & $5(3.6)$ & \\
\hline & $\begin{array}{l}\text { Opium, heroin, and } \\
\text { crystal methamphet- } \\
\text { amine }\end{array}$ & $1.8(2)$ & $7.3(10)$ & \\
\hline & Marijuana & $8(7.1)$ & $9(6.6)$ & \\
\hline \multirow{5}{*}{ Level of consciousness } & Alert & $51(45.1)$ & $56(40.9)$ & \multirow{5}{*}{0.22} \\
\hline & Lethargic & $47(41.6)$ & $54(40.1)$ & \\
\hline & Stupor & $5(4.4)$ & $6(4.4)$ & \\
\hline & Coma & $1(0.9)$ & $8(5.8)$ & \\
\hline & Agitated & $9(8)$ & $12(8.8)$ & \\
\hline \multicolumn{2}{|c|}{ Heart rate (per min) } & $89.36 \pm 12.62$ & $87.87 \pm 17.24$ & $0.7 \epsilon$ \\
\hline \multicolumn{2}{|c|}{ Temperature $\left({ }^{\circ} \mathrm{C}\right)$} & $36.89 \pm 0.21$ & $36.89 \pm 0.32$ & 0.18 \\
\hline \multicolumn{2}{|c|}{ Systolic blood pressure $(\mathrm{mmHg})$} & $123.18 \pm 15.75$ & $123.33 \pm 17.50$ & 0.94 \\
\hline \multicolumn{2}{|c|}{ Diastolic blood pressure $(\mathrm{mmHg})$} & $77.27 \pm 10.21$ & $75.97 \pm 12.22$ & 036 \\
\hline \multicolumn{2}{|c|}{$\mathrm{O}_{2}$ saturation $(\%)$} & $92.05 \pm 22.17$ & $95.44 \pm 26.26$ & 0.28 \\
\hline \multicolumn{2}{|c|}{ Time from ingestion to admission (hour) } & $4.77 \pm 4.54$ & $10.67 \pm 7.09$ & 0.03 \\
\hline \multicolumn{2}{|c|}{ Amount of ingested alcohol $(\mathrm{mL})$} & $366.3 \pm 211.56$ & $409.27 \pm 348.44$ & 0.25 \\
\hline
\end{tabular}


Table 3. Comparing laboratory data between patients with normal and abnormal ECG

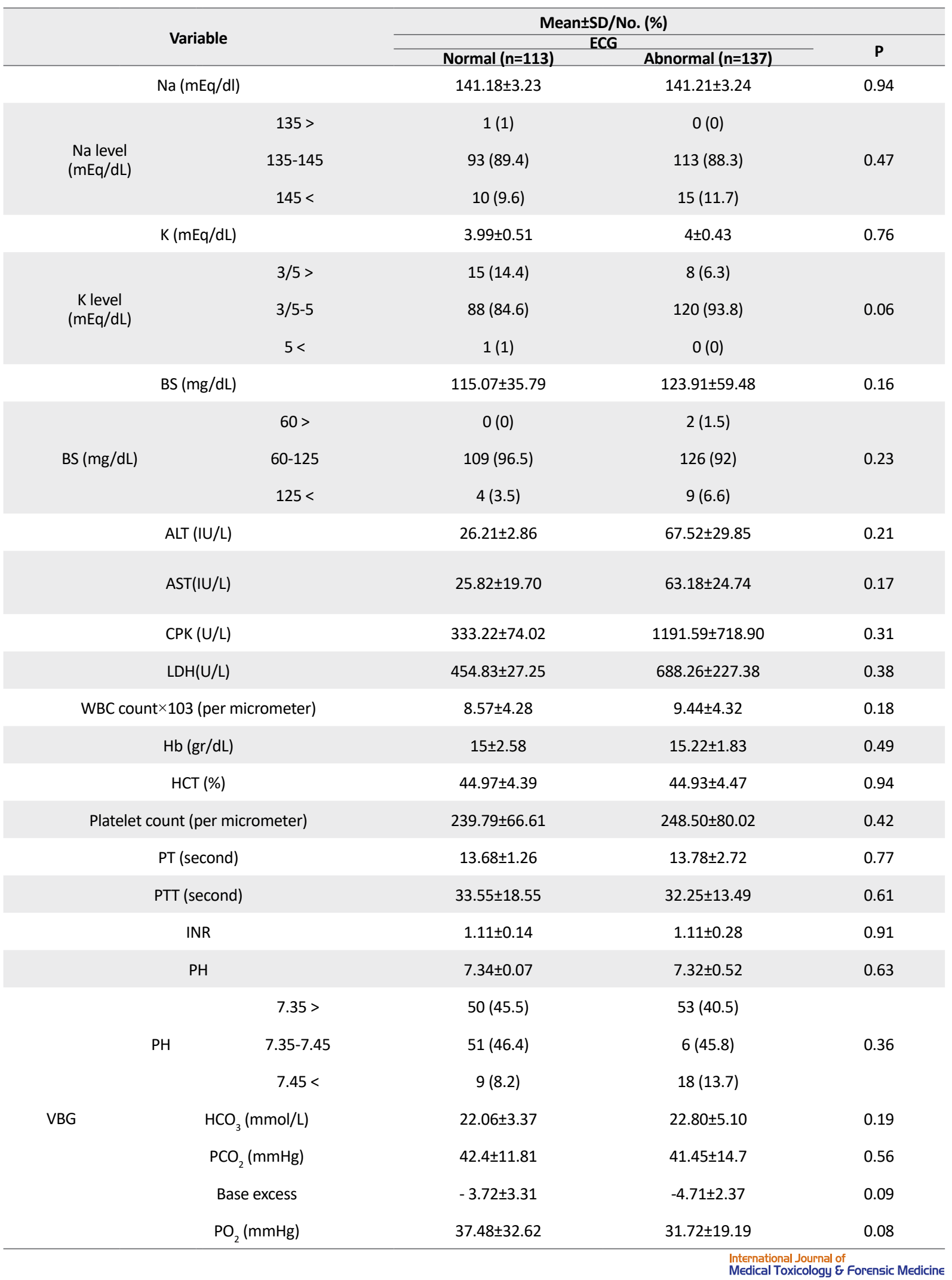

BS: Blood Sugar; AST: Aspartate Aminotransferase; ALT: Alanine Aminotransferase; LDH: Lactate Dehydrogenase; CPK: Creatine Phosphokinase; CBC: Complete Blood Count; and INR, PT, PTT: Coagulation tests; VBG: Venous Blood Gas. 
ter evaluation of this issue. Aasebo et al. reported that most changes in ECG were detected in drunken patients at admission. They argued that these alternations were generally resolved after one day,i.e. more prevalent in the alcohol poisoning group, compared to the controls [17]. In that study, similar to our study, abnormal ECG findings at baseline were reviewed regardless of the time between alcohol consumption and hospitalization. However, in our study, the ECGs were only obtained once for the patients. However, what appears to be consistent among all studies is the association between ethanol blood levels and ECG changes, i.e. directly related to the period of emergency department admission and ECG checks [16-18].

Based on our study, the amount of ingested alcohol in patients with ECG changes was more than those without changes; however, there was no significant difference in this respect. Other studies have reported a direct relationship between ECG changes and the amount of ingested alcohol; there are more ECG changes in patients who consume larger amounts of alcohol [17]. Furthermore, alcohol poisoning leading to hospitalization in our study was due to acute alcohol consumption. Besides, it is possible that our information about the amount of the ingested alcohol, either chronic or acute, which led to hospitalization, has been inaccurate because of indecency and cultural reasons.

Laboratory findings reflected no significant difference between normal and abnormal ECG findings in our study. Borini et al. explored females with alcohol toxicity. They indicated a significant difference in triglyceride, FBS and postprandial blood sugar, potassium, aminotransferases, and Gamma glutamyltransferase between patients with and without changes in ECG; all parameters, except BS, were higher in patients with ECG changes [19]. Some studies have also demonstrated that ECG changes, more particularly in QT interval, are more likely to be the result of electrolyte changes, specifically calcium, hyperbilirubinemia, cardiac ischemia, or hypersensitivity of the autonomic nervous system rather than hepatic injury $[20,21]$. The lack of a classification of patients to chronic and acute consumers may justify that matter.

Hypokalemia is among the common electrolyte alternations in alcohol poisoning [19]. Other studies have inconsistently highlighted its association with ECG changes; some studies have reported it only in concurrence with hypomagnesemia [22]. Age may play an important role as a confounding variable in the laboratory data. The reason for normal laboratory data in our study might be that our patients were young; however, the subjects were middle-aged in other studies.

Moreover, there was no significant difference regarding the vital signs between patients with or without ECG changes. However, Verelst et al. [16] reported an association between decreased blood pressure and consciousness level and ECG changes. The changes of ECG in patients with low consciousness were more prevalent; however, this difference was not significant. Comparing the electrocardiographic parameters, there was no significant difference between the study groups of ECG changes; although P wave, PR segment, QRS complex, and QT interval were longer in patients with abnormal ECG. Alcohol poisoning can lead to prolonged PR, QRS, and QT. Thus, it makes it susceptible to cause atrial arrhythmias or even hazardous ventricular arrhythmias. Atrial fibrillation is among the most frequent findings after alcohol consumption,i.e. induced by prolonged $\mathrm{P}$ wave $[16,23]$. This finding is common in holiday heart syndrome which occurs in patients with high blood alcohol levels [3].

QRS changes were not significantly different according to the study conducted by Aasebo and associates [16]. Evidence demonstrated that QRS complex changes can be considered as a dependent predicting factor of mortality due to ethanol poisoning [24]. Another concordant finding of Aasebo et al. with our study is the lack of difference in the PR segment [17]; however, other studies presented shortened PR segment after alcohol poisoning which decreases after metabolizing alcohol in the liver. the shortening of the PR segment is related to pure ethanol dose and occurs more in higher doses [25].

One of the most hazardous alternations in EEG is the QT interval change, i.e. remarkably followed by lethal arrhythmias. Some studies demonstrated that QT interval reaches from 0.40 second in low blood alcohol level to 0.411 seconds in the ethanol concentration of $0.04 \%$, and 0.426 in the ethanol concentration of $0.08 \%$. These ECG changes are due to ion changes in the canals, i.e. responsible for the activity potential and regulatory molecules of protein receptors $[26,27]$.

A study in Germany in 2017 investigated 4131 participants. Accordingly, breath alcohol concentration was significantly related to cardiac arrhythmias and in particular sinus tachycardia in ECG findings. Additionally, a significant association was observed between chronic alcohol consumption and sinus tachycardia [28]. 
A systematic review in 2018 documented that the most common ECG changes with acute alcohol intoxication are P-wave and QTc prolongation, followed by T-wave abnormalities and QRS complex prolongation. However, most of these findings are completely reversible [18].

\section{Conclusion}

The detected ECG changes were not significant based on the clinical manifestations, laboratory data, and demographic characteristics in patients with acute ethanol poisoning. However, the time interval between ethanol consumption and hospital admission was a significant characteristic and more frequent in patients with abnormal ECG findings. More studies are suggested to be performed for reaching a better conclusion.

\section{Ethical Considerations}

\section{Compliance with ethical guidelines}

This study was approved by the Ethics Committee of Isfahan University of Medical Sciences (Code: IR.MUI. MED.REC.1397.173). All the included patients or their guardians provided a written consent form to participate in this research. All procedures involving the human participant were per the ethical standards of the institutional and or national research committee, the 1964 Helsinki Declaration, and its later amendments or comparable ethical standards. Private information, including name, surname, and burial permit, was removed from the datasheet to comply with ethical concerns.

\section{Funding}

This article was extracted from the MD thesis of Farzaneh Nayeri. dissertation of the third author at the Isfahan Clinical Toxicology Research Center, Isfahan University of Medical Sciences, Isfahan, Iran. (No. 397407).

\section{Author's contributions}

Patient care, data collection, literature review, drafting and submitting the manuscript: Gholmali Dorooshi, Rokhsareh Meamar; Critically reviewed the draft for important intellectual content: Nastaran Eizadi-Mood; Revised it for English style and language: Nastaran Eizadi-Mood; Reviewed and approved the final: All authors.

\section{Conflict of interest}

The authors declared no conflicts of interest.
We want to thank the Toxicology Department Personnel for their contribution to this work.

\section{References}

[1] Piano MR. Alcohol's effects on the cardiovascular system. Alcohol Res. 2017; 38(2):219-41. [PMID] [PMCID]

[2] World Health Organization. Global status report on alcohol and health 2018. Geneva: World Health Organization; 2018. https://www.who.int/publications/i/item/9789241565639

[3] Alinejad S, Zamani N, Abdollahi M, Mehrpour O. A narrative review of acute adult poisoning in Iran. Iran J Med Sci. 2017; 42(4):327-46. https://ijms.sums.ac.ir/article_40460.html

[4] Hoffman RS, Nelson LC, Goldfrank LR, Howland MA, Lewin NA, Smith SW. Goldfrank's toxicologic emergencies. $11^{\text {th }} \mathrm{Ed}$. New York: McGraw-Hill Education; 2019. https:/ / books.google. com/books?id=a6QwswEACAAJ\&dq

[5] George A, Figueredo VM. Alcohol and arrhythmias: A comprehensive review. J Cardiovasc Med (Hagerstown). 2010; 11(4):221-8. [DOI:10.2459/JCM.0b013e328334b42d] [PMID]

[6] Engler R, Ray R, Higgins CB, McNally C, Buxton WH, Bhargava $\mathrm{V}$, et al. Clinical assessment and follow-up of functional capacity in patients with chronic congestive cardiomyopathy. Am J Cardiol. 1982; 49(8):1832-7. [DOI:10.1016/0002-9149(82)90199-0] [PMID]

[7] Thornton J. Atrial fibrillation in healthy non-alcoholic people after an alcoholic binge. Lancet. 1984; 324(8410):1013-5. [DOI:10.1016/S0140-6736(84)91109-7] [PMID]

[8] Marriott HJL. Electrocardiographic abnormalities, conduction disorders and arrhythmias in primary myocardial disease. Prog Cardiovasc Dis. 1964; 7(2):99-114. [DOI:10.1016/S00330620(64)80013-X] [PMID]

[9] Abbasi M, Soltaninejad K. Analyzing toxic chemical components in illegal alcoholic beverages. Int J Med Toxicol Forensic Med. 2020; 10(3):29331. [DOI:10.32598/ijmtfm.v10i3.29331]

[10] Yoonhee C, Jung K, EO E, Lee D, Kim J, Shin D, et al. The relationship between alcohol consumption and injury in ED trauma patients. Am J Emerg Med. 2009; 27(8):956-60. [DOI:10.1016/j. ajem.2008.07.035] [PMID]

[11] Rehm J, Mathers C, Popova S, Thavorncharoensap M, Teerawattananon Y, Patra J. Global burden of disease and injury and economic cost attributable to alcohol use and alcohol-use disorders. Lancet. 2009; 373(9682):2223-33. [DOI:10.1016/S01406736(09)60746-7] [PMID]

[12] Lee MH, Mello MJ, Reinert S. Emergency department charges for evaluating minimally injured alcohol-impaired drivers. Ann Emerg Med. 2009; 54(4):593-9. [DOI:10.1016/j.annemergmed.2009.05.018] [PMID]

[13] Eskandarieh S, Hajebi A, Noroozi A, Haghdoost AA, Baneshi MR. Epidemiology of alcohol abuse in Iran. Asia Pac J Med Toxicol. 2014; 3(1):22. [DOI:10.22038/APJMT.2014.2905]

[14] Calle PA, Damen J, De Paepe P, Monsieurs KG, Buylaert WA. A survey on alcohol and illicit drug abuse among emer- 
gency department patients. Acta Clinica Belg. 2006; 61(4):188-95. [DOI:10.1179/acb.2006.033] [PMID]

[15] Pletcher MJ, Maselli J, Gonzales R. Uncomplicated alcohol intoxication in the emergency department: An analysis of the National Hospital Ambulatory Medical Care Survey. Am J Med. 2004; 117(11):863-7. [DOI:10.1016/j.amjmed.2004.07.042] [PMID]

[16] Verelst S, Moonen PJ, Desruelles D, Gillet JB. Emergency department visits due to alcohol intoxication: Characteristics of patients and impact on the emergency room. Alcohol Alcohol. 2012; 47(4):433-8. [DOI:10.1093/alcalc/ags035] [PMID]

[17] Aasebø W, Erikssen J, Jonsbu J, Stavem K. ECG changes in patients with acute ethanol intoxication. Scand Cardiovasc J. 2007; 41(2):79-84. [DOI:10.1080/14017430601091698] [PMID]

[18] Raheja H, Namana V, Chopra K, Sinha A, Gupta SS, Kamholz $\mathrm{S}$, et al. Electrocardiogram changes with acute alcohol intoxication: A systematic review. Open Cardiovasc Med J. 2018; 12:1-6. [DOI:10.2174/1874192401812010001] [PMID] [PMCID]

[19] Borini P, Terrazas JHI, Ferreira Júnior A, Guimarães RC, Borini SB. [Female alcoholics: Electrocardiographic changes and associated metabolic and electrolytic disorders (Portuguese])]. Arq Bras Cardiol. 2003; 81(5):512-7. [DOI:10.1590/ S0066-782X2003001300007] [PMID]

[20] Patel D, Singh P, Katz W, Hughes C, Chopra K, Němec J. QT interval prolongation in end-stage liver disease cannot be explained by nonhepathic factors. Ann Noninvasive Electrocardiol. 2014; 19:574-81. [DOI:10.1111/anec.12161] [PMID] [PMCID]

[21] Mimidis K, Papadopoulos V, Thomopoulos K, Tziakas D, Ritis K, Dalla V, et al. Prolongation of the QTc interval in patients with cirrhosis. Ann Gastroenterol. 2003; 16:155-8. http://www.annalsgastro.gr/index.php/annalsgastro/article/view/207

[22] Tsuji H, Venditti Jr FJ, Evans JC, Larson MG, Levy D. The associations of levels of serum potassium and magnesium with ventricular premature complexes (the Framingham Heart Study). Am J Cardiol. 1994; 74(3):232-5. [DOI:10.1016/00029149(94)90362-X] [PMID]

[23] Raitt MH, Volgman AS, Zoble RG, Charbonneau L, Padder FA, O'Hara GE, et al. Prediction of the recurrence of atrial fibrillation after cardioversion in the Atrial Fibrillation Follow-up Investigation of Rhythm Management (AFFIRM) study. Am Heart J. 2006; 151(2):390-6. [DOI:10.1016/j. ahj.2005.03.019] [PMID]

[24] Kalahasti V, Nambi V, Martin DO, Lam CT, Yamada D, Wilkoff BL, et al. QRS duration and prediction of mortality in patients undergoing risk stratification for ventricular arrhythmias. Am J Cardiol. 2003; 92(7):798-803. [DOI:10.1016/ S0002-9149(03)00886-5] [PMID]

[25] Lorsheyd A, de Lange DW, Hijmering ML, Cramer MJM, van de Wiel A. PR and OTc interval prolongation on the electrocardiogram after binge drinking in healthy individuals. Neth J Med. 2005; 63(2):59-63. [PMID]

[26] Narahashi T, Kuriyama K, Illes P, Wirkner K, Fischer W, Mühlberg K, et al. Neuroreceptors and ion channels as targets of alcohol. Alcohol Clin Exp Res. 2001; 25(5 Suppl ISBRA):182S-8S. [DOI:10.1097/00000374-200105051-00030] [PMID]
[27] Reed SF, Porges SW, Newlin DB. Effect of alcohol on vagal regulation of cardiovascular function: Contributions of the polyvagal theory to the psychophysiology of alcohol. Exp Clin Psychopharmacol. 1999; 7(4):484-92. [DOI:10.1037/10641297.7.4.484] [PMID]

[28] Brunner S, Herbel R, Drobesch C, Peters A, Massberg S, Kääb S, et al. Alcohol consumption, sinus tachycardia, and cardiac arrhythmias at the Munich Octoberfest: Results from the Munich Beer Related Electrocardiogram Workup Study (MunichBREW). Eur Heart J. 2017; 38(27):2100-6. [DOI:10.1093/eurheartj/ehx156] [PMID] [PMCID] 